\title{
The Prevalence of Chronic Diseases and Multimorbidity in Primary Care Practice: A PPRNet Report
}

\author{
Steven M. Ornstein, MD, Paul J. Nietert, PhD, Ruth G. Jenkins, PhD, \\ and Cara B. Litvin, MD, MS
}

Introduction: Multimorbidity (multiple chronic illnesses) greatly affects the delivery of health care and assessment of health care quality. There is a lack of basic epidemiologic data on multimorbidity in the United States. This article addresses the prevalence of 24 chronic illnesses and multimorbidity from primary care practices across the United States.

Methods: This cross-sectional study was conducted in the PPRNet, a practice-based research network among 226 practices in 43 states that maintains a clinical database derived from a common electronic health record. Practices providing data as of October 1, 2011, and their active adult patients comprised the population used for analyses. The prevalence of each chronic illness and multimorbidity were calculated.

Results: Included in these analyses were 148 practices with 667,379 active patients. Median prevalence across practices ranged from $35.8 \%$ for hypertension to $0.23 \%$ for Parkinson disease, with wide variability among practices for all conditions. Multimorbidity increased steeply with age, leveling off at age 80; overall, $45.2 \%$ of patients had more than one chronic illness.

Conclusion: Multimorbidity is a prevalent problem in primary care practice, a finding with implications for health care delivery and payment, quality assessment, and research. (J Am Board Fam Med 2013;26:518-524.)

Keywords: Chronic Disease, Morbidity, Practice-based Research, Primary Health Care

More research is needed for complex patients, specifically those with multiple chronic conditions (multimorbidity). Two thirds of health care costs are spent on patients with more than one chronic condition. ${ }^{1}$ Multimorbidity also affects the assessment of health care quality, since practice guide-

This article was externally peer reviewed.

Submitted 9 January 2013; revised 8 March 2013; accepted 19 March 2013.

From the Department of Family Medicine (SMO, RGJ), the Division of Biostatistics and Epidemiology, Department of Medicine (PJN), and the Division of General Internal Medicine and Geriatrics, Department of Medicine (CBL), Medical University of South Carolina, Charleston.

Funding: This study was funded by the Agency for Healthcare Research and Quality grant no. 1R24HS019448. Conflict of interest: none declared.

Corresponding author: Steven M. Ornstein, MD, Department of Family Medicine, Medical University of South Carolina, 5 Charleston Center, Suite 263, Charleston, SC 29425 (E-mail: ornstesm@musc.edu).

\footnotetext{
See Related Commentary on Page 484.
}

lines for single conditions typically do not incorporate implications of comorbidity. ${ }^{2}$

Efforts to study multimorbidity in the United States are hampered by a lack of current basic epidemiologic data. A recent review revealed that no prevalence studies have been done in US primary care practices and the 4 general population surveys are 11 to 28 years old. ${ }^{3}$ A 2005 prevalence study of Medicare beneficiaries, which demonstrated that $20 \%$ had $\geq 2$ chronic conditions, was limited by its inclusion of only 6 conditions ${ }^{4}$; a 1999 sample found that $64.7 \%$ and $42.9 \%$ had $\geq 2$ and $\geq 3$ chronic conditions, respectively. ${ }^{5}$

PPRNet, a national primary care practice-based research network, founded in $1995,{ }^{6}$ now comprises 226 practices in 43 states. The PPRNet database is unique among US practice-based research networks; it is derived from the Practice Partner electronic health record (EHR) (McKesson Corp, San Francisco, CA) used by member practices. The database contains anonymized demographic and clinical data and is updated quarterly through automated data extracts. 
In this article we present analyses from the PPRNet database on the prevalence of 24 common chronic diseases, the prevalence of multimorbidity, and the association of multimorbidity with age. To our knowledge, this is the first such report from primary care practices in the United States and is timely given the renewed enthusiasm for invigorating primary care ${ }^{7}$ and the importance of caring for patients with multimorbidity in this setting. ${ }^{8}$

\section{Methods}

This study was a cross-sectional analysis of the PPRNet database as of October 1, 2011. Practices that had begun use of the Practice Partner EHR on or after January 1, 2010, were excluded from the analyses because they might not have had sufficient time to update problem lists for their patients. Practices whose primary specialty was not family practice or general internal medicine or those with fewer than 100 active patients $\geq 18$ years old also were excluded. Patients were defined as active in the practice if there was a progress note recorded in their record within 1 year of October 1, 2011. We excluded patients $<18$ years old, given that the conditions assessed largely affect adults; thus, all active adult patients were included.

Demographic data and all active diagnoses recorded on the EHR problem (major and other) and diagnoses lists were included in the analyses. Since the EHR allows free text in these lists, many diagnoses do not have accompanying diagnostic codes. PPRNet employs both data-mapping computer algorithms using SAS software (SAS, Inc, Cary, NC) for pattern matching and expert review to assign International Classification of Diseases, 9th Revision, Clinical Modification (ICD-9-CM) codes to these diagnoses.9 For example, for hypertension, the computer algorithm searches all problem and diagnosis lists for any of 292 discrete text strings (3 of which are "HTN", "HYPERTNS", "MALIGN HYPERT"), assigns an associated code for hypertension, and flags appropriate entries for human review and corroboration. For the chronic conditions included in this article, we have determined that, compared with review by a clinician, our approach has at least $99 \%$ sensitivity and $99 \%$ specificity for identification of these conditions from diagnoses lists. The chronic conditions included in this report are listed in Table 1.

Analyses were performed at both the patient and practice levels. The prevalence of each condition was calculated by dividing the number of patients with the condition by the number of active patients. The prevalence of morbidity burden, defined as the number of chronic conditions, was calculated by dividing the number of patients with each morbidity burden (eg, $0,1,2, \ldots, 23)$ by the total number of active patients. Multimorbidity was alternatively defined as the presence of $\geq 2$ or $\geq 3$ chronic conditions. The prevalence of multimorbidity was calculated for the entire population and stratified by age and sex. To illustrate the relationship between age and prevalence of multimorbidity, hierarchical logistic regression models were constructed using patient-level data. Models were stratified by sex and multimorbidity definition, and fourth-degree polynomial effects of age (divided by 10) were included in each of the models because these models provided the best fit (as measured using the models' generalized $\chi^{2}$ goodness of fit statistics) when compared with models using polynomial effects of other degrees (eg, 1, 2, 3, or 5). To determine which conditions tended to cluster with each other, additional hierarchical logistic regression models were constructed, with separate models for each of the 276 pairwise combinations of the 24 conditions. For each of these models, an odds ratio (OR) was calculated to quantify the degree of association (clustering) between the 2 conditions of interest. ORs $>8.0$ were considered to be indicative of a strong degree of clustering.

All models were constructed using SAS software version 9.3 (SAS, Inc.) Proc GLIMMIX and accounted for clustering of patients within practices using random practice effects with compound symmetry covariance structures.

\section{Results}

As of October 1, 2011, 172 practices provided data. Eight practices that had begun comprehensive use of the Practice Partner EHR on or after January 1, 2010, were excluded, as were 11 whose primary specialty was not family practice or general internal medicine and 5 because they had fewer than 100 active adult patients. Remaining in the analyses were 148 practices with 667,379 active adult patients. Specialty distribution among the 148 practices was $77.0 \%$ family practice, $16.2 \%$ internal medicine, and $6.8 \%$ combinations of primary care specialists and other physicians. Among the patients, $58.2 \%$ were women and $41.7 \%$ were men; 


\begin{tabular}{|c|c|c|c|}
\hline Chronic Condition & ICD-9-CM Codes* & $\begin{array}{l}\text { Prevalence Among } \\
\text { All Patients, \% (n) }\end{array}$ & $\begin{array}{l}\text { Prevalence Among Practices, } \\
\text { median \% (10th, } 90 \text { th } \\
\text { percentile) }\end{array}$ \\
\hline Hypertension & $362.11,401,402,403,404,405,437.2,997.91$ & $33.51(223,653)$ & $35.77(22.62,53.63)$ \\
\hline Hyperlipidemia & $272.0-272.1,272.3,272.4,277.7$ & $32.97(220,053)$ & $34.74(20.40,55.70)$ \\
\hline Depression & $290.13,290.21,296.2,296.3,298.0,300.4,311$ & $18.67(124,596)$ & $20.15(9.47,30.37)$ \\
\hline $\begin{array}{l}\text { Gastroesophageal } \\
\quad \text { reflux }\end{array}$ & $530.11,530.81,530.85$ & $14.93(99,658)$ & $15.63(6.49,27.39)$ \\
\hline Diabetes mellitus & $250,357.2,362.0,366.41$ & $11.93(79,641)$ & $12.80(6.72,20.31)$ \\
\hline Obesity & $278.09,278.01,278.03,278.8, \mathrm{~V} 85.3, \mathrm{~V} 85.4$ & $11.90(79,407)$ & $9.66(3.31,25.92)$ \\
\hline Osteoarthritis & 715,721 (excluding $721.7,721.8$ ) & $9.93(66,255)$ & $8.95(2.47,21.20)$ \\
\hline Asthma & 493 (excluding 493.81) & $8.73(58,900)$ & $7.99(4.84,14.27)$ \\
\hline $\begin{array}{l}\text { Osteoporosis and } \\
\text { osteopenia }\end{array}$ & $733.0,733.90$ (with text indicating osteopenia) & $6.55(43,700)$ & $5.51(1.96,12.74)$ \\
\hline Migraine & 346 & $5.66(37,756)$ & $5.42(2.70,9.75)$ \\
\hline Coronary disease & $\begin{array}{l}\text { 410, 411, 412, 413, 414, 429.7, P36.0, P36.1, } \\
\text { P36.3, V45.81, V45.82 }\end{array}$ & $4.92(32,867)$ & $4.76(1.50,10.89)$ \\
\hline Atherosclerosis & $\begin{array}{l}290.4,433,434,435,436437.0,437.8,437.9 \\
\text { 438, 440, 441, 442, 443, 444, 445, P38.12, } \\
\text { P38.44, P39.22, P39.24, P39.25, P39.28, } \\
\text { P39.29, V12.54 }\end{array}$ & $4.74(31,638)$ & $4.11(1.44,11.16)$ \\
\hline $\begin{array}{l}\text { Chronic obstructive } \\
\text { pulmonary disease }\end{array}$ & $491,492,496$ & $4.35(29,005)$ & $4.02(1.37,9.29)$ \\
\hline Chronic kidney disease & $\begin{array}{l}250.4,285.21,403,404,581,582,583,585,586 \\
\quad 587,588,996.73, \mathrm{~V} 42.0, \mathrm{~V} 45.1\end{array}$ & $3.37(22,496)$ & $2.55(0.87,8.73)$ \\
\hline $\begin{array}{l}\text { Cerebrovascular } \\
\text { disease }\end{array}$ & $\begin{array}{l}290.4,430,431,432,433,434,435,436,437 \\
\quad 438,439, \mathrm{P} 38.12, \mathrm{P} 38.44, \mathrm{~V} 12.54\end{array}$ & $2.88(19,227)$ & $2.44(0.88,6.78)$ \\
\hline Atrial fibrillation & 427.31 & $2.17(14,487)$ & $2.07(0.69,4.49)$ \\
\hline Heart failure & $\begin{array}{l}402.01,402.11,402.91,404.01,404.03,404.11 \\
\quad 404.13,404.91,404.93,428\end{array}$ & $1.68(11,241)$ & $1.67(0.50,3.76)$ \\
\hline Alcohol use disorders & $\begin{array}{l}291,303,305.0,357.5,425.5,535.3,571.0-571.3 \\
\quad 790.3,980.0,980.9, \text { P } 94.62\end{array}$ & $1.29(8594)$ & $1.30(0.43,3.01)$ \\
\hline Dementia & $\begin{array}{l}\text { 046.1, 290, 291.2, 292.82, 294.1, 330.1, 331.0, } \\
\quad 331.1,331.2,331.82\end{array}$ & $1.10(7361)$ & $0.93(0.27,2.47)$ \\
\hline Peptic ulcer & $531,532,533,534, \mathrm{~V} 12.71$ & $1.09(7242)$ & $0.94(0.19,2.26)$ \\
\hline Chronic liver disease & $\begin{array}{l}070.22,070.23,070.32,070.33,070.44,070.54 \\
155,197.7,571.2,571.4,571.5,571.6,571.8 \\
571.9,572.2,572.4,572.8,996.82, \mathrm{P} 50.4 \\
\text { P50.59, V10.07, V42.7 }\end{array}$ & $1.04(6951)$ & $0.82(0.27,2.55)$ \\
\hline Epilepsy & 345 & $1.03(6893)$ & $1.01(0.36,1.74)$ \\
\hline Rheumatoid arthritis & 714 & $0.95(6357)$ & $0.91(0.37,1.76)$ \\
\hline $\begin{array}{l}\text { Parkinson's disease or } \\
\text { syndrome }\end{array}$ & 332.0 & $0.28(1886)$ & $0.23(0.00,0.67)$ \\
\hline
\end{tabular}

*The International Classification of Diseases, 9th Revision, Clinical Modification (ICD-9-CM) codes were either included in the database diagnoses lists or derived by the PPRNet algorithms (see text). $P$ set before a number indicates a procedure code. Codes used but not listed include G-codes used for quality reporting and procedure codes used for procedures unique to a diagnosis (eg, diabetic eye examination, gastric bypass for obesity).

sex was not recorded for $0.1 \%$ of the patients. The age distribution was 18 to 34 years old, $23.8 \% ; 35$ to 44 years old, $15.9 \%$; 45 to 54 years old, $19.4 \%$; 55 to 64 years old, $18.8 \%$; 65 to 74 years old, $12.1 \%$; 75 to 84 years old, $7.0 \%$; and $\geq 85$ years old, $3.0 \%$.

Table 1 shows patient- and practice-level variation in prevalence among and within the 24 chronic conditions studied. The most common diagnoses, affecting nearly one third of the patients, were hyperlipidemia and hypertension. Depression was diagnosed in nearly one fifth of all patients and gastroesophageal reflux disease (GERD) in nearly one sixth. There was substantial variability in the prevalence of many conditions among practices, with 2- to 12-fold variations between the 10th and 
Table 2. Number of Chronic Conditions Among 667,379 Active Patients and 148 Practices as of October 1, 2011

\begin{tabular}{lcc}
\hline $\begin{array}{l}\text { Chronic } \\
\text { Conditions } \\
\text { (n) }\end{array}$ & $\begin{array}{c}\text { Patients in All } \\
\text { Practices, \% (n) }\end{array}$ & $\begin{array}{c}\text { Prevalence Among Practices, } \\
\text { Median (10th, 90th } \\
\text { Percentile) }\end{array}$ \\
\hline 0 & $34.65(231,235)$ & $30.11(14.02,47.66)$ \\
1 & $20.10(134,136)$ & $19.76(12.88,24.92)$ \\
2 & $14.89(99,367)$ & $15.47(12.01,18.59)$ \\
3 & $11.18(74,586)$ & $11.86(7.61,15.48)$ \\
4 & $7.67(51,163)$ & $8.44(4.00,12.76)$ \\
5 & $4.89(32,652)$ & $5.36(1.93,9.90)$ \\
6 & $2.97(19,821)$ & $3.07(0.94,6.54)$ \\
7 to 23 & $3.66(24,419)$ & $0.31(0.04,1.05)$ \\
\hline
\end{tabular}

90th percentiles. For some conditions, such as hypertension, hyperlipidemia, GERD, diabetes, depression, and asthma, the variations were 2-to 3 -fold; for others such as peptic ulcer, osteoarthritis, dementia, chronic renal disease, and chronic liver disease, the variations were 9-fold or more.

Table 2 displays the morbidity burden among all patients and across practices. Almost two thirds of all patients had one or more chronic conditions. Defined as the presence of $\geq 2$ chronic conditions, $45.2 \%$ of patients would be considered to have multimorbidity; using the definition requiring the presence of $\geq 3$ chronic conditions, $30.3 \%$ have this designation. Across the practices, findings were similar, indicating that caring for patients with multimorbidity is common in primary care.

Table 3 shows multimorbidity by age group and definition and Figure 1 shows it by age, sex, and definition. As expected, multimorbidity, irrespective of how it is defined, increased with age and is similar among men and women at the same age. In the youngest age group, multimorbidity was uncommon. By age 50, the prevalence of multimorbidity is about $40 \%$ if defined as $\geq 2$ chronic conditions and about $25 \%$ if defined as $\geq 3$ chronic conditions. By age 80 , multimorbidity was present in at least two thirds of the sample, regardless of its definition.

In all the hierarchical logistic regression models, the linear, quadratic, cubic, and quartic effects of age were highly statistically significant $(P<.0001)$, indicating that the shapes of the curves of multimorbidity prevalence as a function of age can best be expressed with 4th degree polynomials. Ageand sex-specific prevalence rates as estimated by the logistic regression models are illustrated in Figure 1 ; as the graph depicts, multimorbidity seems to increase curvilinearly with age, plateauing at about age 85 and becoming less common for those aged 90 to 100 years.

Eighteen diagnostic pairs were strongly associated with each other. Most of these strong associations were expected. Four occurred because certain diagnoses contain multiple conditions. For example, the diagnosis of hypertensive chronic kidney disease (ICD-9-CM code 403) incorporates hypertension and chronic kidney disease. Similarly, vascular dementia (ICD-9-CM code 290.4) incorporates cerebrovascular disease and dementia. Other strong associations were found between atherosclerosis and hypertension, coronary heart dis-

Table 3. Prevalence of Multimorbidity by Age and Definition Among All 667,379 Active Patients and 148 Practices as of October 1, 2011

\begin{tabular}{|c|c|c|c|c|c|}
\hline \multirow[b]{2}{*}{ Age (Years) } & \multicolumn{2}{|c|}{$\geq 2$ Chronic Conditions } & \multicolumn{2}{|c|}{$\geq 3$ Chronic Conditions } & \multirow[b]{2}{*}{$\begin{array}{l}\text { Chronic Conditions, } \\
\text { Median (IQR) }\end{array}$} \\
\hline & $\begin{array}{l}\text { Patients in All } \\
\text { Practices* }\end{array}$ & $\begin{array}{c}\text { Prevalence Among } \\
\text { Practices }^{\dagger}\end{array}$ & $\begin{array}{l}\text { Patients in All } \\
\text { Practices* }\end{array}$ & $\begin{array}{l}\text { Prevalence Among } \\
\text { Practices }^{\dagger}\end{array}$ & \\
\hline $18-34$ & $13.85(22,025)$ & $14.21(6.58,28.98)$ & $4.97(7911)$ & $4.93(1.86,13.60)$ & $0(0-1)$ \\
\hline $35-44$ & $29.83(31,683)$ & $32.50(16.47,55.43)$ & $15.10(16,032)$ & $15.73(6.58,34.54)$ & $1(0-2)$ \\
\hline $45-54$ & $44.82(58,022)$ & $47.48(26.69,69.97)$ & $26.88(34,794)$ & $27.90(11.76,50.78)$ & $1(0-3)$ \\
\hline $55-64$ & $61.00(76,684)$ & $66.01(41.19,81.93)$ & $71.92(52,594)$ & $44.62(24.20,65.33)$ & $2(1-4)$ \\
\hline $65-74$ & $74.30(59,902)$ & $78.74(54.12,91.57)$ & $57.35(46,231)$ & $60.63(35.55,79.34)$ & $3(1-4)$ \\
\hline $75-84$ & $80.99(37,668)$ & $87.26(60.32,96.50)$ & $67.51(31,402)$ & $73.79(42.80,88.39)$ & $4(2-5)$ \\
\hline$\geq 85$ & $80.82(16,024)$ & $87.30(61.55,98.34)$ & $68.99(13,677)$ & $75.66(44.09,92.69)$ & $4(2-6)$ \\
\hline
\end{tabular}

*Data are \% (n).

${ }^{\dagger}$ Data are median (10th, 90th percentile).

$\mathrm{IQR}$, interquartile range. 
Figure 1. Multimorbidity prevalence by age, stratified by sex. Prevalence rates were estimated using hierarchical logistic regression models (see Methods for details).

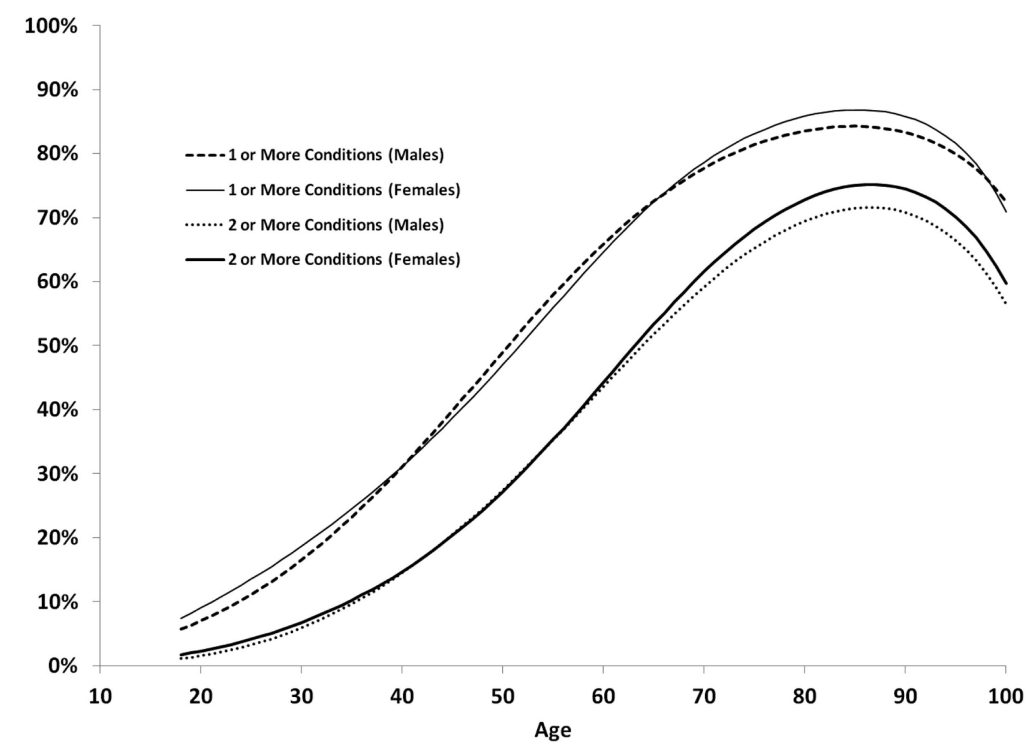

ease (CHD), diabetes mellitus, and hyperlipidemia; between atherosclerosis, CHD, and congestive heart failure $(\mathrm{CHF})$; between atrial fibrillation and $\mathrm{CHF}$; between $\mathrm{CHF}$ and chronic obstructive pulmonary disease; between CHD and hyperlipidemia; and between Parkinson disease and dementia.

\section{Discussion}

This report on the prevalence of 24 common chronic illnesses and multimorbidity among 667,379 patients in 148 primary care practices is the first such study in the United States. Although there was considerable variability in the prevalence of specific conditions and the prevalence of multimorbidity, the most salient finding is that multimorbidity is a common presentation in primary care practice. Indeed, for most practices it is more likely that a patient will have multimorbidity than only one or no chronic problems.

These finding emphasizes the challenges faced by primary care clinicians as they endeavor to incorporate acute care, preventive services, chronic disease management, and behavioral health in their care delivery portfolios. Most clinical guidelines do not currently incorporate specific recommendations for patients with comorbidities. ${ }^{2,10}$ There is also limited evidence of the effectiveness of interventions to improve care for patients with multimorbidity, and identifying these patients is a requisite first step when designing interventions and developing guidelines to improve their outcomes. ${ }^{11}$ From a policy perspective, this study also supports recent discussion of the need to focus care of individuals with multimorbidity on patient-centered goals, adopt quality measures to reflect this focus, and align clinical systems and payment mechanisms to support such care. ${ }^{12}$

Given the absence of similar studies from primary care practice settings, it is challenging to compare our findings with others. Many studies use self-reported data rather than analyses of practice records and others are based on samples of practice records. Nonetheless, our reported chronic condition prevalences were similar to those in other studies for hypertension, hyperlipidemia, and asthma or chronic obstructive pulmonary disorder, ${ }^{13}$ atrial fibrillation, ${ }^{14}$ coronary disease ${ }^{15}$ depression, ${ }^{16}$ diabetes, ${ }^{17}$ epilepsy, ${ }^{18}$ GERD,${ }^{19}$ heart failure, ${ }^{20}$ symptomatic osteoarthritis, ${ }^{21}$ peptic ulcer disease, ${ }^{22}$ and rheumatoid arthritis. $^{23}$ Compared with national estimates, the prevalence of alcohol use disorders ${ }^{24}$ and chronic kidney disease ${ }^{25}$ is lower in our population. There is limited comparable data for migraine and Parkinson disease, and data for dementia and osteoporosis or osteopenia ${ }^{26}$ are for noncomparable age groups. Our findings on the prevalence of multimorbidity are comparable to earlier primary care studies from the Netherlands ${ }^{27}$ and Canada. ${ }^{28}$ 
There are several important limitations to this study. PPRNet practices represent a nonrandom sample of users of a common EHR, and our findings may not be generalizable to all US primary care. As with all record reviews-EHR or otherwise-findings are dependent on the fidelity with which actual patient diagnoses are recorded. It may be that primary care clinicians chose not to include in the EHR chronic conditions treated by physicians outside of their practice. Measures of multimorbidity are sensitive to the number of chronic conditions included in the study, and this study did not include some important conditions, such as anxiety disorders and malignancies. ${ }^{29}$ Despite these limitations, our findings that most chronic diseases and multimorbidity prevalence were similar to those found in other studies is reassuring. In addition, a recent review suggested including $\geq 12$ chronic diseases to calculate a stable measure of prevalence ${ }^{3}$; our approach, using 24 chronic diseases, clearly meets this criterion.

Our observation that multimorbidity seemed to plateau at age 80 and decline beginning at age 90 is puzzling. It may be that once patients reach these ages, their physicians no longer endeavor to make or record new chronic illnesses. It could also be that patients with extended longevity tend to be less ill than those who die at younger ages.

In any study of comorbidity, it is important to consider the issue of definition. Although in this study we chose the definition of either $\geq 2$ or $\geq 3$ chronic conditions, an alternative is simply to use counts of conditions and represent comorbidity as a continuous rather than categorical variable. ${ }^{30}$ This approach is easy to adopt with databases such as the one we use in PPRNet.

\section{Conclusion}

This report from primary care provides practicebased estimates about the prevalence of 24 chronic conditions and confirms that multimorbidity is common in these settings. Its findings should help inform further research, the development of quality metrics and health care policy, and the care of patients with multimorbidity.

\section{References}

1. Anderson G. Chronic Care: Making the Case for Ongoing Care. 2010; http://www.rwjf.org/en/researchpublications/find-rwjf-research/2010/02/chronic-care. html. Accessed July 3, 2012.
2. Boyd CM, Darer J, Boult C, Fried LP, Boult L, Wu AW. Clinical practice guidelines and quality of care for older patients with multiple comorbid diseases: implications for pay for performance. JAMA 2005; 294:716-24.

3. Fortin M, Stewart M, Poitras ME, Almirall J, Maddocks H. A systematic review of prevalence studies on multimorbidity: toward a more uniform methodology. Ann Fam Med 2012;10:142-51.

4. Schneider KM, O'Donnell BE, Dean D. Prevalence of multiple chronic conditions in the United States' Medicare population. Health Qual Life Outcomes 2009;7:82.

5. Wolff JL, Starfield B, Anderson G. Prevalence, expenditures, and complications of multiple chronic conditions in the elderly. Arch Intern Med 2002;162: 2269-76.

6. Ornstein S, Jenkins J. The Practice Partner Research Network: description of a novel national research network of computer-based patient records users. Carolina Health Serv Policy Rev. 1997;4:145-51.

7. Iglehart JK. Primary care update-light at the end of the tunnel? New Enlg J Med 2012;366:2144-6.

8. Starfield B. Challenges to primary care from co- and multi-morbidity. Prim Health Care Res Dev 2011; $12: 1-2$.

9. Jenkins R, Ornstein S, Wessell A, Litvin C, Nietert $\mathrm{P}$, Riley J. Enhancing strategies to identify complex patients on primary care EHR data. Fam Med 2012; 44(Suppl 1):10.

10. Lugtenberg M, Burgers JS, Clancy C, Westert GP, Schneider EC. Current guidelines have limited applicability to patients with comorbid conditions: a systematic analysis of evidence-based guidelines. PloS one. 6(10):e25987, 2011.

11. Smith SM, Soubhi H, Fortin M, Hudon C, O'Dowd T. Managing patients with multimorbidity: systematic review of interventions in primary care and community settings. BMJ 2012;345:e5205.

12. Tinetti ME, Fried TR, Boyd CM. Designing health care for the most common chronic condition-multimorbidity. JAMA 2012;307:2493-4.

13. Wilper AP, Woolhandler S, Lasser KE, McCormick D, Bor DH, Himmelstein DU. A national study of chronic disease prevalence and access to care in uninsured U.S. adults. Ann Intern Med. 2008;149: $170-6$.

14. DeWilde S, Carey IM, Emmas C, Richards N, Cook DG. Trends in the prevalence of diagnosed atrial fibrillation, its treatment with anticoagulation and predictors of such treatment in UK primary care. Heart 2006;92:1064-70.

15. Centers for Disease Control and Prevention (CDC). Prevalence of heart disease-United States, 2005. MMWR Morbid Mortal Wkly Rep 2007;56: $113-8$.

16. Kessler RC, Berglund P, Demler O, Jin R, Merikangas KR, Walters EE. Lifetime prevalence and age- 
of-onset distributions of DSM-IV disorders in the National Comorbidity Survey Replication. Arch Gen Psychiatry 2005;62:593-602.

17. Centers for Disease Control and Prevention. National diabetes fact sheet: national estimates and general information on diabetes and prediabetes in the United States, 2011. Atlanta, GA: U.S. Department of Health and Human Services, Centers for Disease Control and Prevention; 2011.

18. Kobau R, Zahran H, Thurman DJ, et al. Epilepsy surveillance among adults-19 States, Behavioral Risk Factor Surveillance System, 2005. MMWR Surveill Summ 2008;57:1-20.

19. Farup C, Kleinman L, Sloan S, et al. The impact of nocturnal symptoms associated with gastroesophageal reflux disease on health-related quality of life. Arch Intern Med 2001;161:45-52.

20. Redfield MM, Jacobsen SJ, Burnett JC Jr, Mahoney DW, Bailey KR, Rodeheffer RJ. Burden of systolic and diastolic ventricular dysfunction in the community: appreciating the scope of the heart failure epidemic. JAMA 2003;289:194-202.

21. Pereira D, Peleteiro B, Araujo J, Branco J, Santos RA, Ramos E. The effect of osteoarthritis definition on prevalence and incidence estimates: a systematic review. Osteoarthritis Cartilage 2011;19:1270-85.

22. Sung JJ, Kuipers EJ, El-Serag HB. Systematic review: the global incidence and prevalence of peptic ulcer disease. Aliment Pharmacol Ther 2009;29: 938-46.
23. Helmick CG, Felson DT, Lawrence RC, et al. Estimates of the prevalence of arthritis and other rheumatic conditions in the United States. Part I. Arthritis Rheum 2008;58:15-25.

24. Willenbring ML, Massey SH, Gardner MB. Helping patients who drink too much: an evidence-based guide for primary care clinicians. Am Fam Physician 2009;80:44-50.

25. Levey AS, Stevens LA, Schmid CH, et al. A new equation to estimate glomerular filtration rate. Ann Intern Med 2009;150:604-12.

26. Siris ES, Miller PD, Barrett-Connor E, et al. Identification and fracture outcomes of undiagnosed low bone mineral density in postmenopausal women: results from the National Osteoporosis Risk Assessment. JAMA 2001;286:2815-22.

27. Uijen AA, van de Lisdonk EH. Multimorbidity in primary care: prevalence and trend over the last 20 years. Eur J Gen Pract 2008;14(Suppl 1):28-32.

28. Fortin M, Bravo G, Hudon C, Vanasse A, Lapointe L. Prevalence of multimorbidity among adults seen in family practice. Ann Fam Med 2005;3:223-8.

29. Siegel R, DeSantis C, Virgo K, et al. Cancer treatment and survivorship statistics, 2012. CA Cancer J Clin 2012;62:220-41.

30. Huntley AL, Johnson R, Purdy S, Valderas JM, Salisbury C. Measures of multimorbidity and morbidity burden for use in primary care and community settings: a systematic review and guide. Ann Fam Med 2012;10:134-41. 